\title{
RESÍDUOS SÓLIDOS URBANOS DISPOSTOS EM TERRENOS BALDIOS DA CIDADE
}

\author{
DE CHAPECÓ, SC
}

SOLID URBAN WASTE DISPOSED IN VACANT LOTS OF CHAPECÓ CITY, SC

Luana Melim Neves ${ }^{1}$

Junir Antonio Lutinski²

Jéssica Tiburski ${ }^{3}$

Recebido em: 19 jul. 2017

Aceito em: 08 jun. 2018

RESUMO: Entre os problemas ambientais provenientes do desenvolvimento atual destacase o aumento da geração de resíduos sólidos urbanos (RSU). Estes resíduos estão associados à poluição e impactam a saúde humana. Este estudo teve como objetivo caracterizar os RSU depositados em terrenos baldios (TB) da cidade de Chapecó (SC) quanto à frequência, a origem e a classificação. Foram avaliados 100 TB em 10 bairros da cidade, no período entre maio e junho de 2016. Foi verificada a presença de RSU em $72 \%$ dos terrenos avaliados. A origem foi identificada como residencial em $65 \%$ dos casos, da construção civil em $30 \%$, de origem comercial em $23 \%$ e industrial em $1 \%$. Quanto à classificação, resíduos a classe IIA (resíduos não perigosos não inertes) foram identificados em $52 \%$ dos TB, resíduos pertencentes à classe IIB (resíduos inertes) foram registrados em $49 \%$ e resíduos perigosos em $9 \%$. Os resultados indicam a necessidade de o município ampliar o gerenciamento de RSU e de uma política pública integrada envolvendo todos os segmentos da sociedade para a gestão dos mesmos. Os resultados desse estudo poderão subsidiar ações para o desenvolvimento social e econômico do município bem como para a conservação dos recursos naturais e das condições de saúde da comunidade. Recomenda-se um programa de educação ambiental e fiscalização voltada para mobilização da comunidade em prol a separação e destinação correta dos RSU.

Palavras-chave: Contaminação do solo. Degradação ambiental. Educação ambiental. Gestão ambiental. Urbanização.

ABSTRACT: Among the environmental problems arising from population growth are the increase in the generation of urban solid waste (RSU). These wastes are associated with pollution and impact human health. The aim of this study was to characterize the RSU deposited in vacant lots (TB) in the Chapecó city (SC) regarding frequency, origin and classification. A total of 100 TB were evaluated in 10 city districts between May and June 2016. The presence of RSU was verified in $72 \%$ of the evaluated lots. The identified origin was residential in $65 \%$ of cases, civil construction in $30 \%$, commercial origin in $23 \%$ and industrial in $1 \%$. Class IIA (non-inert nonhazardous waste) was identified in $52 \%$ of TB, class IIB (inert waste) was recorded in $49 \%$ and hazardous waste in $9 \%$. This study indicates the need for the municipality to

\footnotetext{
1 Acadêmica do curso de Ciências Biológicas da Universidade Comunitária da Região de Chapecó (UNOCHAPECÓ). E-mail: luana.mneves@unchapeco.edu.br. Projeto de Pesquisa de Iniciação Científica (PIBIC). Fundo de Apoio á pesquisa da Unochapecó (FAPE), Edital n 010 Reitoria/2016.

2 Professor Doutor do Programa de Pós-Graduação em Ciências da Saúde da Universidade Comunitária da Região de Chapecó (UNOCHAPECÓ). E-mail: junir@unochapeco.edu.br.

3 Acadêmica do curso de Ciências Biológicas da Universidade Comunitária da Região de Chapecó (UNOCHAPECÓ). jessica.tiburski@unochapeco.edu.br.
} 
improve RSU management and an integrated public policy involving all segments of society for manage them. The results of this study may subsidize actions for the social and economic development of the municipality as well as for the conservation of natural resources and community health conditions. It is recommended an environmental education and inspection program aimed at mobilizing the community in favor of the separation and correct RSU destination.

Keywords: Soil contamination. Environmental degradation. Environmental education. Environmental management. Urbanization.

\section{INTRODUÇÃO}

A geração de resíduos sólidos urbanos (RSU) está associada ao modelo de desenvolvimento econômico atual, ao crescimento populacional, ao acelerado processo de urbanização e às mudanças tecnológicas (BESEN, 2011). A popularização das embalagens descartáveis e a busca pela praticidade e por maior agilidade na vida das pessoas têm contribuído para o aumento na geração de resíduos e para o volume depositado nos aterros pelo mundo (FERES, RODRIGUES, 2012). A prática de disposição e acúmulo de RSU em terrenos baldios (TB) contribui como fonte de proliferação de vetores de doenças, especialmente roedores e insetos, os quais encontram abrigo e alimento nesses locais (LOPES, LEITE e PRASAD, 2000). Soma-se a isso a poluição visual, o mau cheiro, a contaminação do ambiente e os riscos à saúde humana (MUCELIN e BELLINI, 2008; DEUS, BATTISTELLE e SILVA, 2015).

De acordo com a NBR10004/2004 e a Política Nacional de Resíduos Sólidos, Lei no 12. 305, de 2 de agosto de 2010, regulamentada pelo decreto 7.404, de 23 de dezembro de 2010, os RSU são constituídos por materiais inorgânicos e orgânicos, de constituição heterogênea, resultantes da natureza e das atividades humanas. Os RSU vêm se tornando um problema sanitário, ambiental, econômico e social (KGATHI e BOLAANE, 2001; SIQUEIRA e ASSAD, 2015). São produzidas aproximadamente 1,3 bilhões toneladas ao ano no mundo o que demanda cada vez mais espaços para destinação, principalmente nos grandes centros urbanos (ROMANSINI, 2005; CNI, 2014). A Política Nacional dos Resíduos Sólidos visa amenizar os impactos negativos dos RSU não tratados ou destinados de forma inadequada (FERES e RODRIGUES, 2012).

A origem dos resíduos sólidos está vinculada às residências, comércios, indústrias, serviços da saúde, limpeza pública e construção civil (BRASIL, 2008). Segundo a NBR 10004/2004, os RSU são classificados em resíduos Classe I (Perigosos): aqueles que apresentam inflamabilidade, corrosividade, reatividade, toxicidade ou patogenicidade, ou seja, aqueles que apresentam risco à saúde pública, provocando mortalidade, incidência de doenças ou acentuando seus índices ou riscos ao meio-ambiente, quando gerenciados de forma inadequada. Os resíduos Classe II (não perigosos) subdividem-se em resíduos classe II A (não inertes) e resíduos classe II B (inertes). Os RSU classe IIA apresentam propriedades de biodegradabilidade, combustibilidade ou solubilidade em água. Os resíduos classe IIB são aqueles resíduos que não apresentam nenhum de seus 
constituintes solubilizáveis a concentrações superiores aos padrões de potabilidade da água.

Tendo em vista a complexidade que envolve a gestão dos RSU, algumas alternativas têm sido propostas ao longo das últimas décadas, dentre as quais se destacam os processos de reciclagem e reutilização desses materiais (RENOU et al., 2008). Embora essas técnicas tenham contribuído e gerado renda para catadores, os aterros sanitários continuam sendo o destino para a disposição de RSU em todo o Brasil e na maior parte dos países da América Latina (CASTILHO e BARCELÓ, 2001; BRASIL, 2008). Ainda que a utilização de aterros sanitários seja considerada um método seguro, este processo de disposição de resíduos produz subprodutos que geram impactos no meio ambiente, principalmente no solo. Os resíduos passam por processos de decomposição tanto química como biológica, e ao final desse processo, dão origem a efluentes líquidos e gasosos, os quais podem ser prejudiciais à saúde humana (LOPES, 2005).

Apresar dos incentivos à coleta seletiva, a aplicação de políticas de reuso, reciclagem e reaproveitamento, é fundamental a destinação ambientalmente correta para aqueles RSU que não podem ser reaproveitados de alguma forma. O apelo para isso está associado à proteção da saúde pública e da qualidade do meio ambiente (HEGEL e CORNÉLIO, 2013). A disposição de RSU de forma inadequada em terrenos baldios, às margens de ruas ou em cursos d'água fazem com que o principal poluente desses resíduos, o chorume, afete a qualidade da água dos mananciais tanto superficiais como subterrâneas (ROCHA e NISHIYAMA, 2012). Alguns RSU têm sido descritos como potenciais criadouros para larvas de mosquitos como o Aedes aegypti (Linnaeus 1762), transmissor da Dengue, Zika vírus e febre Chikungunya (LUTINSKI et al., 2013). Quando lançados em córregos, impedem o fluxo da água causando um dos maiores problemas nas cidades, as enchentes, que causam a perda de materiais e entupimentos de córregos. A proliferação de roedores está associada à destinação inadequada dos RSU e pode favorecer a ocorrência de doenças como a leptospirose, impactando a saúde humana (PORTO, 2001; DEUS, LUCA e CLARKE, 2004).

Diante desse contexto, o presente estudo teve como objetivo caracterizar os RSU depositados em terrenos baldios da cidade de Chapecó (SC) quanto à frequência, a origem e a classificação.

\section{MATERIAL E MÉTODOS}

\section{LOCAL DE ESTUDO}

O município de Chapecó (2705’47"S, 52³7'6”W) situa-se na região oeste do Estado de Santa Catarina, a aproximadamente 600 km de Florianópolis (Figura 1). Caracteriza-se como um polo agroindustrial do sul do Brasil. Representa o centro econômico, político e 
cultural do oeste do catarinense. Conta com uma área urbana de 625,60 km² (CHAPECÓ, 2015) e uma população estimada em 205.789 habitantes (IBGE, 2015). Existem aproximadamente 3.500 terrenos baldios na cidade. Estes se encontram cobertos por vegetação rasteira, gramíneas e pequenos arbustos, bem como áreas remanescentes de vegetação nativa (CHAPECÓ, 2015).

Figura 1 - Localização geográfica do município de Chapecó, SC.

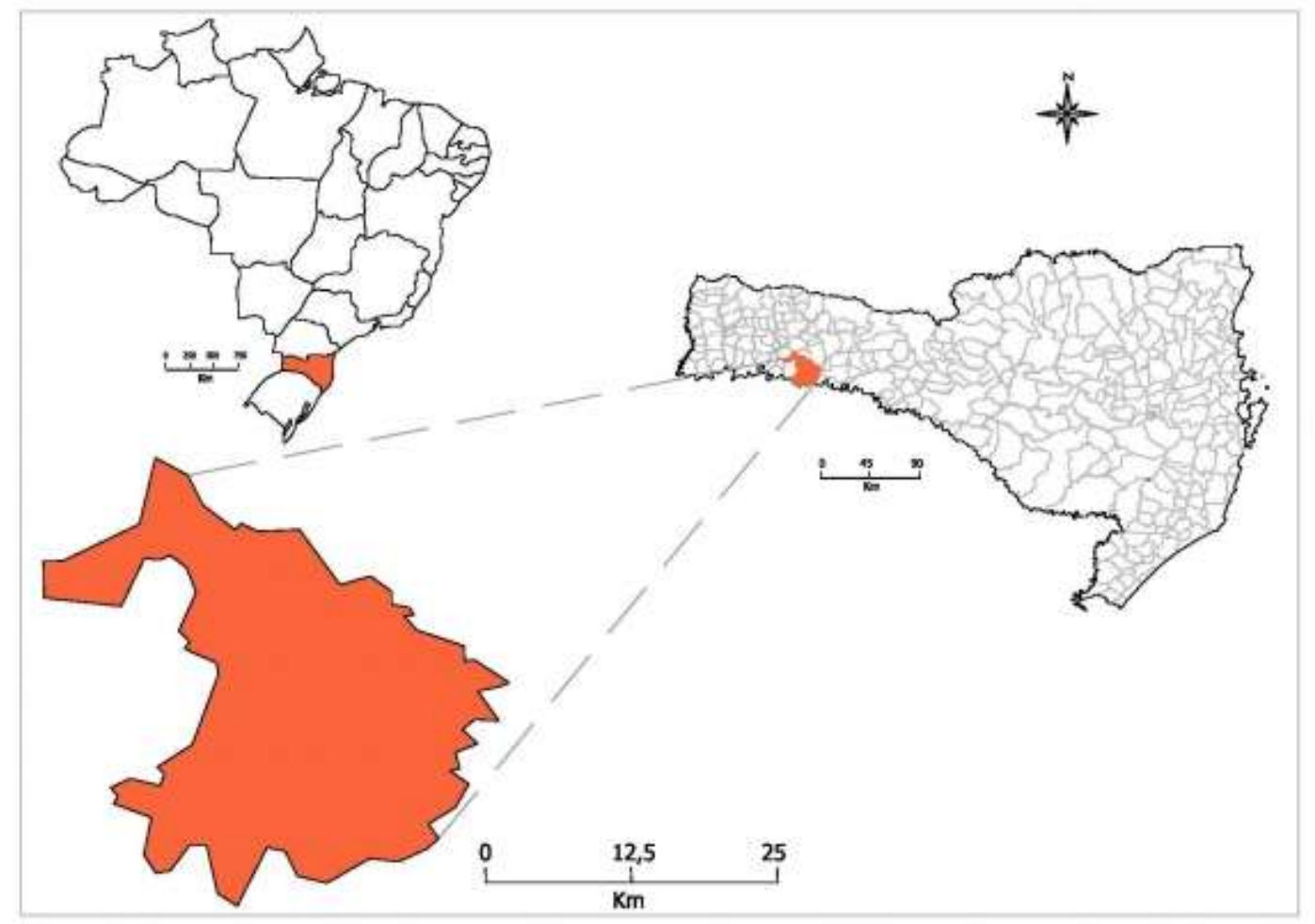

Fonte: IBGE, 2015.

\section{COLETA DE DADOS}

A coleta de dados foi realizada no período de maio a junho de 2016. O estudo foi desenvolvido em 10 bairros previamente selecionados a partir do cadastro de Reconhecimento Geográfico do Programa Municipal de Prevenção à Dengue (PMCD). Foram selecionados bairros distribuídos aproximadamente equidistantes, distribuídos em toda a zona urbana do Município. Os bairros representam 30\% dos bairros da cidade. $\mathrm{Na}$ região sul foi incluído o Bairro Seminário. Na região Oeste, os Bairros Efapi e Parque das Palmeiras. Na região Norte, os Bairros Alvorada, Eldorado e Líder. A região Leste foi contemplada pelos Bairros São Pedro e Bom Pastor. Na região central foram incluídos os Bairros Maria Goretti e Passo dos Fortes.

Foi avaliado um total de 100 TB, sendo um número de 10 por bairro. A escolha dos TB em cada bairro deu-se de forma aleatória a partir de sorteio dentre os TB cadastrados pelo PMCD. Para a caracterização dos RSU quanto a origem e classificação foi utilizada uma lista de verificação construída pelos próprios autores com base na NBR 10004 (ABNT, 
2004). A identificação quanto à origem deu-se conforme Casarin (2013) e classificação de acordo com a NBR 10004 (ABNT, 2004) e Beck (2009). O acesso aos TB foi efetuado concomitantemente com o trabalho das Agentes de Combate às Endemias da Secretaria de Saúde do Chapecó. Pequenos objetos metálicos, papeis, plásticos e vidros foram recolhidos em sacos plásticos e pesados em balança digital portátil no próprio TB. Embalagem de pesticidas, lâmpadas, pilhas e baterias, espumas, isopor, madeiras (fragmentos maiores de1m), pneus, peças de automóveis, roupas e calçados foram contados. Resíduos orgânicos e entulhos da construção civil foram registrados quanto à presença ou ausência.

\section{ANÁLISE DE DADOS}

Os dados foram tabulados e organizados em um banco de dados utilizando-se o Software Excel for Windows. Foi realizada uma análise estatística exploratória baseada nas frequências, ilustrada por tabelas e gráficos e mantidos aqueles que melhor responderam aos objetivos propostos. A associação dos RSU (isopor, metais, papeis, vidros e plásticos) com os bairros foi avaliada através de uma Análise de Componentes Principais (PCA). Os dados foram previamente transformados em $\log (x+1)$, padronizados e analizados com 0 auxílio do programa estatístico Past (HAMMER, HARPER e RIAN, 2001). Os demais resíduos foram excluídos da análise em função da irregularidade apresentadas nas amostras.

\section{RESULTADOS}

Ao todo, em $72 \%$ dos TB foram encontrados RSU. Observou-se uma diversidade quanto à origem, com destaque para a residencial (65\%), seguido por resíduos da construção civil (30\%), comercial (23\%) e industrial (1\%) (Figura 2). Os resíduos sólidos de origem residencial foram representados pelos resíduos orgânicos, móveis, eletrodomésticos e vestimentas. Dentre os resíduos da construção civil destacam-se latas de tinta, tijolos, azulejos e madeiras. De origem comercial, as peças de veículos, baterias, pneus e borrachas. 
Figura 2 - Percentual em relação à origem dos RSU encontrados no município de Chapecó, SC no período de maio a junho de 2016.

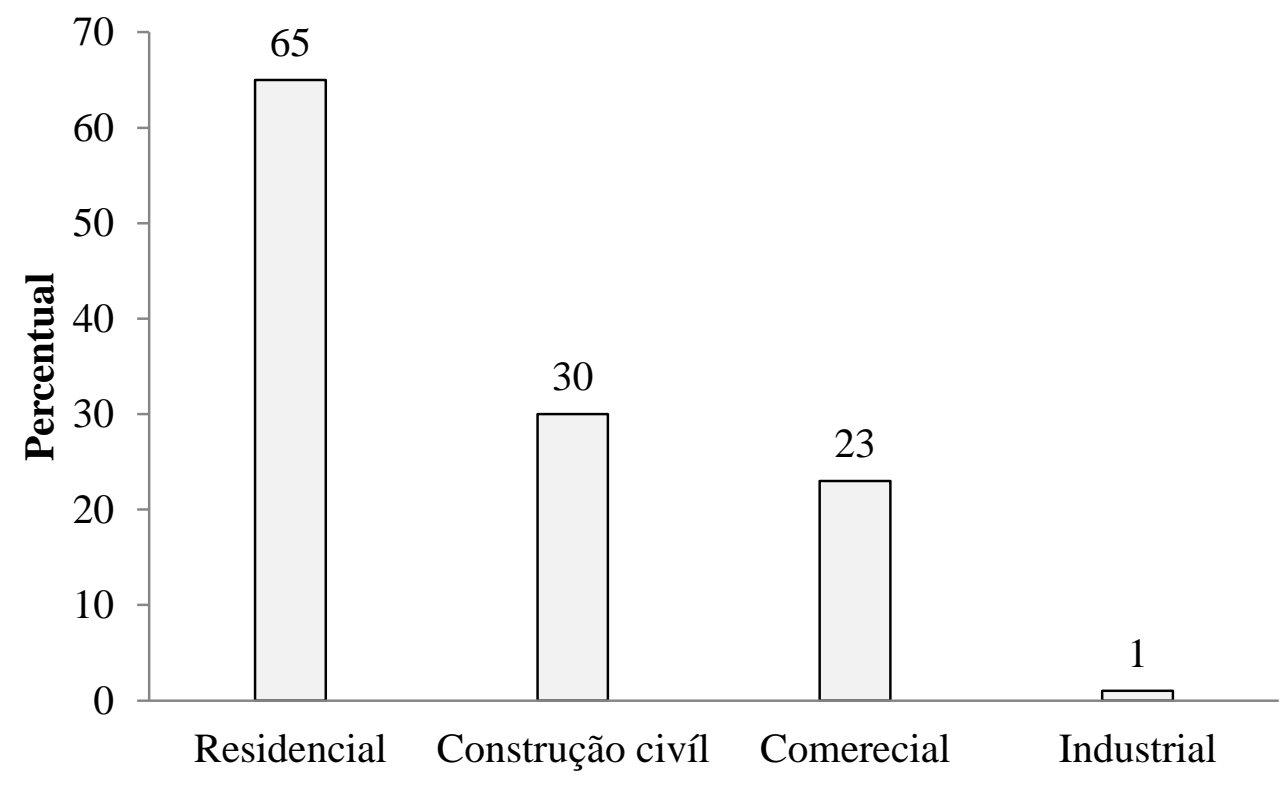

Origem

Quanto à classificação dos RSU, a classe IIA foi a mais abundante com 52\%, seguido da classe IIB com 49\% e resíduos perigosos com 9\% (Figura 3).

Figura 3 - Percentual em relação à classificação dos Resíduos sólidos encontrados no município de Chapecó, SC nos períodos de maio a junho de 2016.

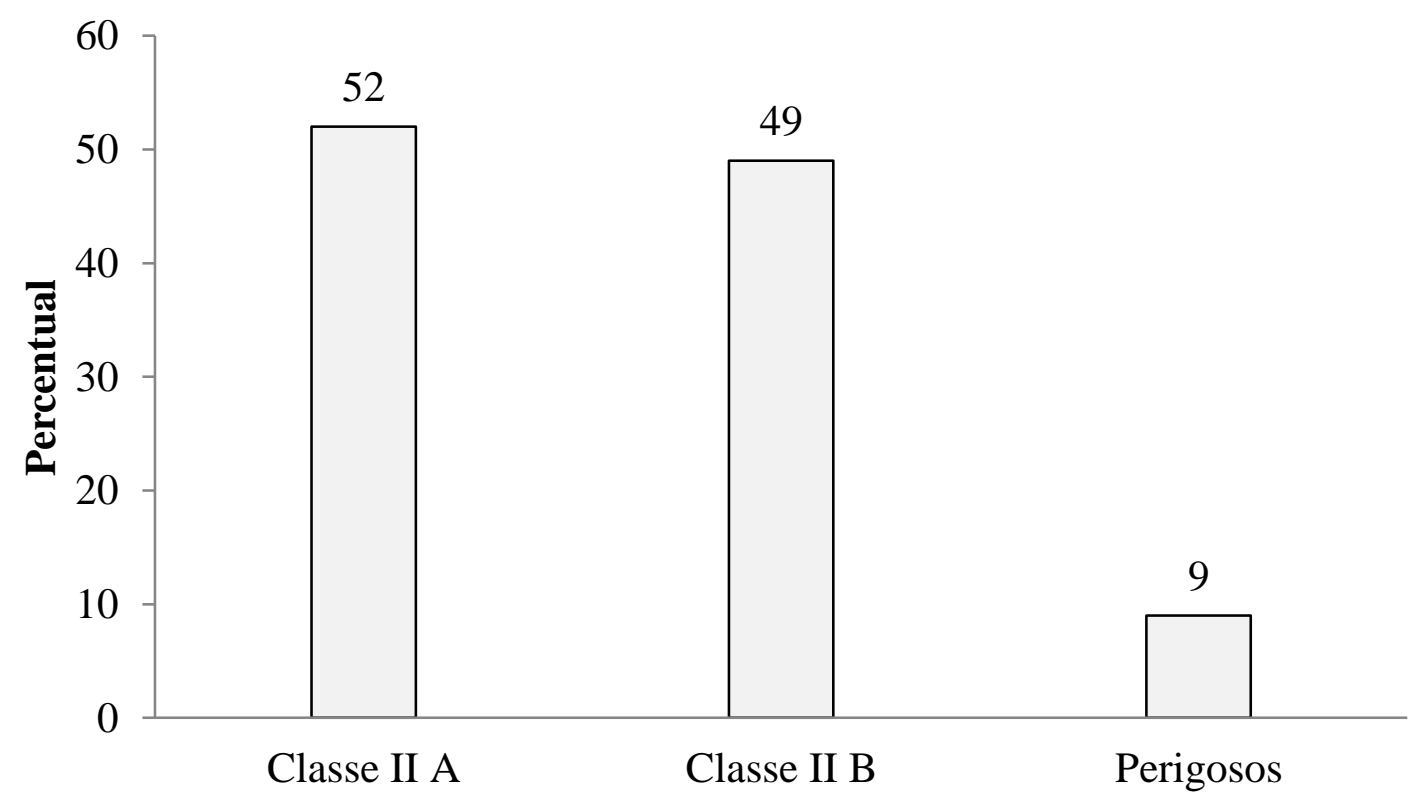

\section{Classificação}

Os resíduos perigosos foram representados por lâmpadas, pilhas e baterias e embalagens de pesticidas. Resíduos pertencentes à classe IIA foram representados majoritariamente por plásticos (40\%), papel (34\%) e metais (29\%). Resíduos da classe IIB foram representados por vidros (35\%) e por entulhos da construção civil em (30\%) (Tabela $1)$. 
Tabela 1 - Frequência dos resíduos encontrados em terrenos baldios no município de Chapecó (SC), maio e junho de 2016.

\begin{tabular}{lll}
\hline Classificação & $\begin{array}{l}\text { Frequência (\%) } \\
\text { nos TB }\end{array}$ & $\begin{array}{l}\text { Média } \pm \text { EP } \\
\text { (unidades ou peso) }\end{array}$ \\
\hline Classe I - Resíduos perigosos & & \\
Embalagem de pesticidas (unidades) & 3 & $0,03 \pm 0,02$ \\
Lâmpadas (unidades) & 4 & $0,07 \pm 0,04$ \\
Pilha e baterias (unidades) & 2 & $0,04 \pm 0,03$ \\
Resíduos não perigosos & & \\
Classe Il A (não inertes) & & \\
Espumas (unidades) & 8 & $0,29 \pm 0,13$ \\
Isopor (unidades) & 18 & $0,43 \pm 0,12$ \\
Madeiras (unidades) & 13 & $0,88 \pm 0,30$ \\
Metais (kg) & 29 & $0,78 \pm 0,23$ \\
Orgânicos & 18 & \\
Papel (kg) & 34 & $0,63 \pm 0,13$ \\
Pneus (unidades) & 2 & $0,02 \pm 0,01$ \\
Plástico (kg) & 40 & $3,60 \pm 0,75$ \\
Peças de automóveis (unidades) & 14 & $0,20 \pm 0,06$ \\
Roupas e calcados (unidades) & 16 & $1,36 \pm 0,88$ \\
Outros (unidades) & 16 & $0,25 \pm 0,07$ \\
Classe II B (inertes) & & \\
Entulhos da construção civil & 30 & $1,36 \pm 0,51$ \\
Vidro (kg) & 35 &
\end{tabular}

Os resíduos de isopor e metais ocorreram positivamente associados com as amostras localizadas nos Bairros Seminário (região sul) e Líder (região norte), enquanto que os resíduos como papel, vidro e plástico se associaram de forma positiva com os Bairros Eldorado (região norte) e Maria Goretti (região central). Os demais resíduos ocorreram independentemente dos bairros avaliados. 
Figura 4 - Associação pelo método de Análise de Componentes Principais (PCA), dos RSU em TB de 10 Bairros do município de Chapecó, no período de maio a junho de 2016.

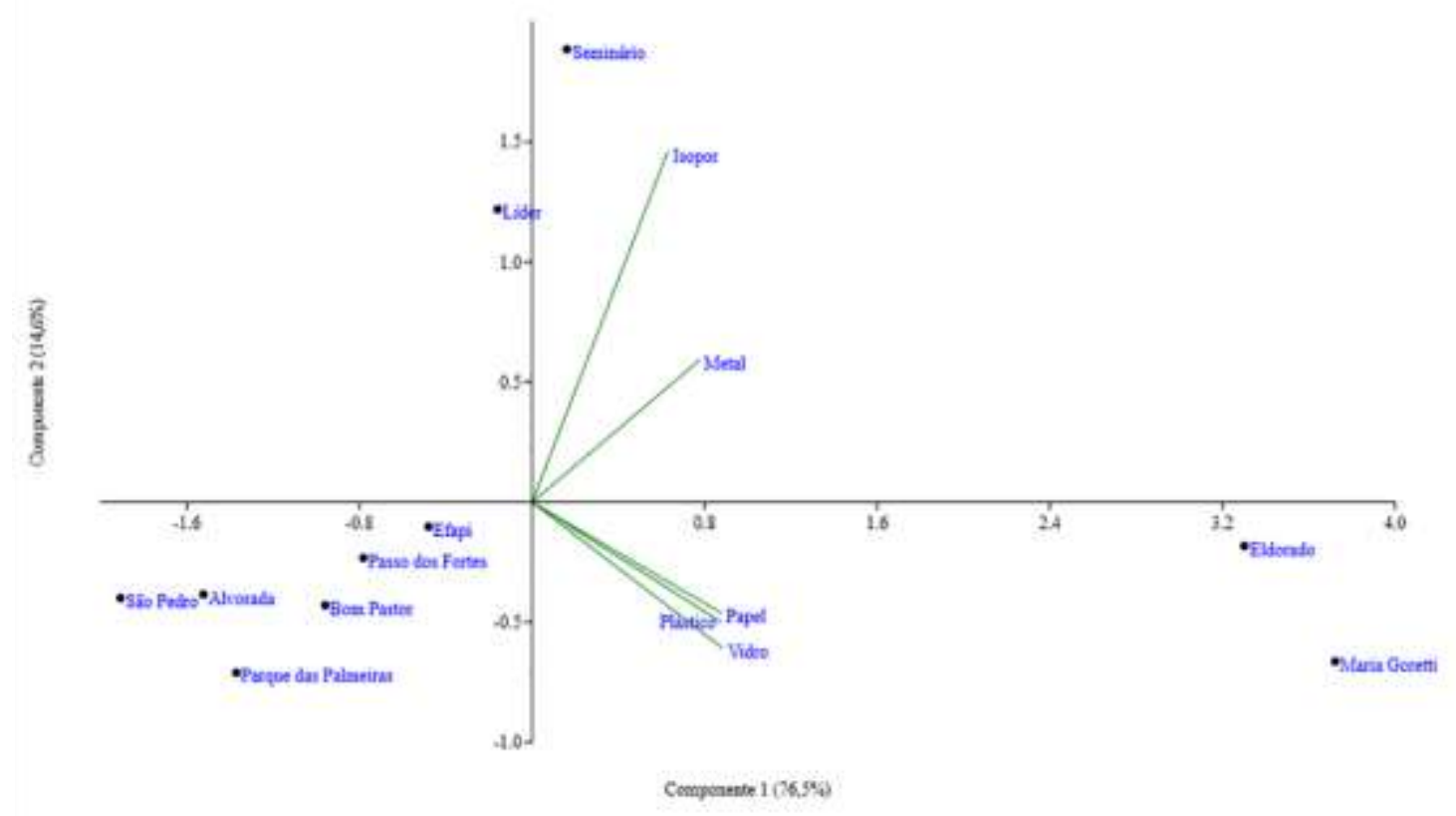

\section{DISCUSÃO}

Foram encontrados RSU em 72 dos 100 TB avaliados. Resíduos de origem residencial foram observados com maior frequência assim como aqueles pertencentes à classe IIA (não perigosos e não inertes). Chama a atenção a presença de resíduos perigosos em $9 \%$ dos TB. A ocorrência dos RSU foi verificada de forma heterogênea entre as regiões da cidade, sendo que quatro bairros apresentaram associações claras com resíduos específicos. Os TB dos demais seis bairros apresentaram os RSU, independentemente do tipo e quantidade.

Sobre a frequência da disposição de RSU em TB, Costa e Fonseca (2009) e Jacobi e Basen (2011) relatam que a geração de resíduos vem aumentando pela diversidade cada vez maior das atividades e demandas humanas. A carência de ações de educação ambiental voltadas para a sensibilização da população quanto à gestão ambientalmente correta dos RSU de origem doméstica podem explicar a elevada ocorrência de resíduos desta natureza nos TB (JACOBI, 2003). A frequência com que foram registrados RSU da construção civil e de origem comercial indicam fragilidades no processo de fiscalização pelos órgãos responsáveis.

Os danos causados pelo descarte de RSU vão além dos impactos sobre a sustentabilidade ambiental e sobre a saúde humana. Delmont (2007) descreve o descarte de RSU como desperdício de matérias primas. Materiais como papéis, plásticos, metais, pneus, vidros, espumas, madeiras e isopor podem ser reciclados ou reutilizados para outras finalidades reduzindo o impacto ambiental sobre as fontes primárias destes recursos na natureza. A separação adequada na origem pode evitar a contaminação dos resíduos e 
agregar maior valor aos RSU recicláveis (NEVES, 2017). A mistura de resíduos orgânicos junto com materiais recicláveis compromete a efetividade do trabalho dos catadores, eleva os riscos de contaminação e de doenças para estes trabalhadores e potencializa a proliferação de roedores e de insetos onde os resíduos são depositados (LUTINSKI e SOUZA, 2009).

Mascarenhas (2009) descreve que o acúmulo inadequado dos RSU agride diretamente 0 meio ambiente. A amostragem de resíduos perigosos representa um indicativo dos riscos à saúde pública e ao comprometimento da qualidade ambiental. $\mathrm{A}$ disposição inadequada de embalagens de pesticidas, lâmpadas, pilhas e baterias nos TB destaca a necessidade de avaliação da efetividade local dos instrumentos legais que determinam a logística reversa destes resíduos, assim como da sensibilização da população para a destinação correta. A contaminação do solo e da água representa a principal ameaça que dos resíduos Classe I (GALBIATI, 2001).

Chapecó vem apresentando elevados índices de infestação pelo mosquito $A$. aegypti e, dentre os fatores ambientais predisponentes, observa-se como a principal causa o lixo depositado em quintais, TB e espaços públicos (LUTINSKI et al., 2013). Este cenário fez com que o município tivesse que enfrentar seguidos surtos de Dengue e, em 2016 uma epidemia desta doença. Casos de febre Chikungunya e Zika vírus também tem sido registrados (LUTINSKI et al., 2013; SANTA CATARINA, 2016). Materiais como plásticos, pneus, objetos de metal e isopor estão entre os mais importantes criadouros para este vetor e frequentes nas amostras deste estudo, indicando a importante associação entre os RSU depositados nos TB e os riscos à saúde da população. Situação semelhante tem sido registrada para os casos de leptospirose, transmitida por roedores.

Hegel e Cornélio (2013) retratam a relação de interdependência dos catadores e do processo de gestão dos RSU. Os catadores encontram na reciclagem uma forma de subsistência ao passo que a geração cada vez mais complexa dos RSU e a busca pela sustentabilidade ambiental demandam de trabalhadores que façam o serviço da separação, reaproveitamento e reciclagem. Embora existam 14 centros de reciclagem na cidade de Chapecó, uma população de aproximadamente 500 catadores e um plano municipal de gestão dos resíduos (CHAPECÓ, 2015), fica evidente, a partir dos resultados encontrados, a fragilidade na participação e responsabilização da sociedade no processo de gestão dos RSU. O percentual de TB com RSU e a diversidade destes resíduos quanto à origem e classificação permitem inferir que há um descomprometimento da população, apesar das campanhas voltadas para a conservação ambiental e para a prevenção dos agravos à saúde decorrentes da gestão inadequada dos RSU.

A presença de RSU em TB de todas as regiões da cidade aponta a necessidade de campanhas amplas de mobilização da sociedade em torno do tema. A região central conta com contêineres para a deposição dos RSU, separados em recicláveis e inorgânicos. Nos bairros periféricos estão situados todos os centros de reciclagem. Todo o município conta com a coleta regular de RSU orgânicos e recicláveis em dias alternados e amplamente divulgados. O município conta com um Ecoponto específico para a gestão dos 
pneus inservíveis e um centro para recebimento de móveis inutilizados, eletrônicos, podas de árvores, entulhos e outros (CHAPECÓ, 2015). Contudo, isso não parece ser o suficiente para que resíduos de diferentes naturezas sejam descartados em TB, independentemente do zoneamento.

\section{CONCLUSÃO}

Os resultados apontam a necessidade de efetivação do plano municipal de gestão de resíduos. Fica evidente a necessidade de campanhas educativas regulares para a separação e para a destinação ambientalmente correta dos RSU, tanto de origem residencial, quanto comercial e da prestação de serviços. Fica evidente o descompromisso da população com a conservação do ambiente e a prevenção de agravos à saúde ao depositarem RSU de diferentes classificações em TB da cidade.

Além da implantação do plano municipal de gestão de resíduos pela administração pública, fica evidente a necessidade da responsabilização da sociedade civil e organizada como parceiros na gestão. Cabe ao poder público a fiscalização e a imputação das sanções legais previstas na legislação aos casos omissos.

A gestão dos RSU também envolvem questões sociais e culturais. As questões socioeconômicas podem explicar a deposição de RSU em TB pela impossibilidade de levar pneus, móveis e resíduos da construção civil até os pontos de coleta ou a contratação de serviços especializados para esta destinação. Questões culturais podem explicar o não reconhecimento por algumas pessoas de que a disposição de RSU em TB representam os problemas que de fatos se constituem.

Os resultados deste estudo apontam fragilidades na gestão participativa dos resíduos na cidade de Chapecó. Apesar dos esforços da administração pública, materializados pelas campanhas educativas e pelo trabalho dos Agentes Comunitários de Saúde e Agentes de Combate às Endemias, a maioria dos TB da cidade representam locais para depósitos para RSU. A compreensão destas fragilidades poderá subsidiar as ações da gestão dos RSU, campanhas de educação ambiental e de responsabilização social. Os resultados podem também servir como base teórica para a fundamentação das políticas públicas de gestão dos RSU em outros municípios e estados. No que tange os resíduos perigosos, os resultados apontam para a necessidade de uma reflexão acerca da efetividade das políticas de logística reversa no Brasil como um todo.

\section{REFERÊNCIAS}

ABNT. NBR 10004: Classificação dos resíduos sólidos. Rio de Janeiro, Associação Brasileira de Normas Técnicas, 2004.

BECK, C. G. Problemática dos resíduos sólidos urbanos do município de João Pessoa: 
Aplicação do Modelo P-E-R. Qualit@s Revista Eletrônica, v. 8, n. 3, p. 1-15, 2009.

BESEN, G. R. Coleta seletiva com inclusão de catadores: construção participativa de indicadores e índices de sustentabilidade. Faculdade de Saúde Pública da USP. 274 f. Tese (pós-graduação), 2011.

BRASIL, Ministério da Saúde. Comissão Nacional sobre Determinantes Sociais da Saúde. As causas sociais das iniquidades em Saúde no Brasil - Relatório Final. 2008. CNDSS. Disponível em:

<http://determinantes.saude.homolog.bvs.br/lildbi/docsonline/6/1/016-Relatorio.pdf.> Acesso em: 10 fev. 2016.

CASTILHO, M.; BARCELÓ, D. Charactherization of organic pollutants in textile wasterwaters and landfill leachate by using toxicity - based fractionnation methods followed br liquid gas chromatography coupled to mass spectrometric detection. Analytical chemical acta, v.426, p.253-264, 2001.

CHAPECÓ. Prefeitura de Chapecó. 2015. Disponível em:< https://www.chapeco.sc.gov.br/.> Acesso em: 15 nov. 2016.

CNI, Confederação Nacional da Indústria. Visão da indústria Brasileira sobre a Gestão de resíduos sólidos. Brasília: CNI, 2014. 218p.

COSTA, W. M. da; FONSECA, M. C. G. da. A importância do gerenciamento dos resíduos hospitalares e seus aspectos positivos para o meio ambiente. Hygeia, v. 5, n. 9, p. 12- 31, 2009.

DELMONT, L. G. Análise dos impactos econômicos oriundos da reciclagem de resíduos sólidos urbanos para a economia brasileira no ano de 2004: uma abordagem insumo-produto. Universidade Federal da Bahia, Dissertação (Mestrado em Economia). 2007. 114 p.

DEUS, R. M.; BATTISTELLE, R. A. G.; SILVA, G. H. R. Resíduos sólidos no Brasil: contexto, lacunas e tendências. Engenharia Sanitária e Ambiental, v. 20, n. 4, p. 685698, 2015.

DEUS, A. B. S. de; LUCA, S.J . de; CLARKE, R. T. Índice de Impacto dos Resíduos Sólidos Urbanos na Saúde Publica (IIRSP): Metodologia e aplicação. Engenharia Sanitária e Ambiental, v. 9, n. 4, p. 329- 334, 2004.

FERES, A.; RODRIGUES, K. P. F. Um click sobre a vida dos catadores de materiais recicláveis no lixão de Vilhena. Rondônia: Universidade federal de Rondônia, Monografia de Bacharelado. 2012. 97 p.

GALBIATI, A. F. Gerenciamento integrado de resíduos sólidos e reciclagem. Instituto de Permacultura Cerrado-Pantanal, 2001. $10 \mathrm{p}$.

HAMMER, O.; HARPER, D. A. T.; RIAN, P. D. Past: Palaeonthological statistics software package for education and data analysis. Versão1.37. 2001. Disponível em: <http://palaeo-electronica.org/2001_1/past/issue1_01.htm>. Acesso em: 23 mar. 2016.

HEGEL, C. G. Z.; CORNÉLIO, P. F. O. Resíduos sólidos urbanos: depósitos irregulares 
no munícipio de Passo Fundo, Rio Grande do Sul, Brasil. Revista de gestão e sustentabilidade ambiental, v. 2, n. 1, p. 5-19, 2013.

IBGE. Estimativa da população por município de Santa Catarina. 2015. Disponível em: <ftp://ftp.ibge.gov.br>. Acesso em: 08 fev. 2015.

JACOBI, P. Educação ambiental, cidadania e sustentabilidade. Cadernos de Pesquisa, v. 118, p. 189-205, 2003.

JACOBI, P. R.; BESEN, G. R. Gestão de resíduos sólidos em São Paulo: desafios da sustentabilidade. Estudos avançados, v. 25, n. 71, p. 135-158, 2011.

KGATHI, D. L.; BOLAANE, B. Instruments for sustainable solid waste management in Botswana. Waste Management \& Research, v. 19, p. 342-353, 2001.

LOPES, J. Estudos da potencialidade de processos oxidativos avançados, isolados e integrados com processos biológicos tradicionais para tratamento de chorume de aterro sanitário. Curitiba: Universidade Federal do Paraná, Dissertação (mestrado). 2005. 229 p.

LOPES, W. S.; LEITE, V. D.; PRASAD, S. Avaliação dos impactos ambientais causados por lixões: um estudo de caso. In: Congresso de Engenharia Sanitária e Ambiental, 2000, Porto Alegre. Anais... Porto Alegre/RS: ABES, p.1-7, 2000.

LUTINSKI, J. A.; ZANCHET, B.; GUARDA, C.; CONSTANCI, C.; FRIEDRICH, D. V.; CECHIN, F. T. C.; BONES, I. A.; SOUZA, M. F. de; BALSAN, S. T.; ZARYCHTA, S. M.; BUSATO, M. A. Infestação de mosquito Aedes aegypti (Diptera: Culicidae) na cidade de Chapecó - SC. Biotemas, v. 26. n. 2, p. 143-151, 2013.

LUTINSKI, J. A.; SOUZA, M. F. Avaliação do sistema de coleta de resíduos recicláveis realizado por catadores e suas implicações sociais, econômicas, ambientais e sanitárias na cidade de Chapecó - SC. Faculdades Alternativas Santo Augusto, Monografia (pós- graduação). 2009. 56p.

MASCARENHAS, L. M. A. Meio Ambiente: a configuração dos riscos da modernidade e os direitos difusos. Revista dos Tribunais, v. 14, n. 54, p. 185-204, 2009.

MUCELIN, C. A.; BELLINI, M. Lixo e impactos ambientais perceptíveis no ecossistema urbano. Sociedade \& Natureza, v. 20, n. 1, p. 111-124, 2008.

NEVES, L. M.; LUTINSKI, J. A.; QUADROS, S. O. de.; BUSATO, M. A.; FERRAZ, L. Catadores de materiais recicláveis: perfil social e riscos à saúde associados ao trabalho. Hygeia, v. 13, n. 24, p. 162-174, 2017.

PORTO, M. F. A. Aspectos Qualitativos do Escoamento Superficial em Áreas Urbanas. In: TUCCI, C. E. M.; PORTO, R. L. L.; BARROS, M. T. Drenagem Urbana. Porto Alegre: Ed. Universidade/UFRGS/ABRH, 2001.

RENOU, S.; GIVAUDAN, S.; POULAIN, F.; DIRASSOUYAN, P.; MOULIN, P. Landifill leachate treatment: review and opportunity. Journal of Hazardous Materials, v. 150, p. 468- 493, 2008.

ROCHA, L.; NISHIYAMA, L. Qualidade das águas superficiais e subterrâneas em 
voçoroca ocupada por resíduos sólidos urbanos - Uberlândia (MG). Observatorium: Revista Eletrônica de Geografia, v. 4, n. 12, p. 107-127, 2012.

ROMANSINI, S. R. M. O catador de resíduos sólidos recicláveis no contexto da sociedade moderna. Criciúma: Universidade do Extremo Sul Catarinense, Dissertação (pós - graduação). 2005.69 p.

SANTA CATARINA. Diretoria de Vigilância Epidemiológica (DIVE). Secretaria de Estado da Saúde: Superintendência de Vigilância em Saúde. Informações Dengue. 2016 Disponível em: http://www.dive.sc.gov.br/conteudos/zoonoses. Acesso em: 10 abr. 2016.

SIQUEIRA, T. M. O. de; ASSAD, M. L. R. C. L. Compostagem de resíduos sólidos urbanos no estado de São Paulo (Brasil). Ambiente \& Sociedade, v. XVIII, n. 4 p. 243264, 2015. 